Received Date : 12-Jun-2014

Revised Date : 31-Aug-2014

Accepted Date : 02-Sep-2014

Article type : Primary Research Articles

\title{
Survival of Norway spruce remains higher in mixed stands under a dryer and warmer climate
}

\section{Running head: Survival of Norway spruce in climate change}

Susanne Neuner ${ }^{1}$, AXel Albrecht ${ }^{2}$, Dominik Cullmann ${ }^{2}$, Friedrich Engels ${ }^{3}$, Verena C. GRIESS $^{4}$, W. ANDREAS HAHN ${ }^{1}$, MARC HANEWINKEL ${ }^{5,6}$, FABIAN HÄRTL ${ }^{1}$, CHRISTIAN KÖLLING ${ }^{7}$, KAI STAUPENDAHL ${ }^{8}$, THOMAS KNOKE ${ }^{1}$

${ }^{1}$ Institute of Forest Management, Center of Life and Food Sciences Weihenstephan, Technische Universität München, Hans-Carl-von-Carlowitz-Platz 2, 85354 Freising, Germany

${ }^{2}$ Forest Research Institute Baden-Württemberg, Wonnhaldestr. 4, 79100 Freiburg, Germany ${ }^{3}$ Research Institute for Forest Ecology and Forestry Rhineland-Palatinate - FAWF, Hauptstrasse 16, 67705 Trippstadt, Germany

Department of Forest Resources Management, Faculty of Forestry, The University of British Columbia, ForestSciences Centre, 2424 Main Mall, Vancouver, British Columbia V6T $1 Z 4$

${ }^{5}$ Swiss Federal Research Institute (WSL), Zürcherstrasse 111, 8903 Birmensdorf, Switzerland ${ }^{6}$ Chair of Forestry Economics and Planning, University of Freiburg, Tennenbacherstr. 4, 79106 Freiburg Germany

${ }^{7}$ Bavarian State Institute of Forestry (LWF), Hans-Carl-v.-Carlowitz-Platz 1, 85354 Freising, Germany

${ }^{8}$ ARGUS Forstplanung, Hinterm Berg 1a, 27726 Worpswede, Germany

This article has been accepted for publication and undergone full peer review but has not been through the copyediting, typesetting, pagination and proofreading process, which may lead to differences between this version and the Version of Record. Please cite this article as doi:

10.1111/gcb.12751

This article is protected by copyright. All rights reserved. 
Correspondence: Susanne Neuner, tel. +49 93526089980, email: susanne.neuner@tum.de

Key Words: climate effects, tree species mixture, soil conditions, survival probability, risk, forest management

\section{Primary research article}

\section{Abstract}

Shifts in tree species distributions caused by climatic change are expected to cause severe losses in the economic value of European forestland. However, this projection disregards potential adaptation options such as tree species conversion, shorter production periods, or establishment of mixed species forests. The effect of tree species mixture has, as yet, not been quantitatively investigated for its potential to mitigate future increases in production risks. For the first time we use survival time analysis to assess the effects of climate, species mixture and soil condition on survival probabilities for Norway spruce and European beech. Accelerated Failure Time (AFT) models based on an extensive dataset of almost 30,000 trees from the European Forest Damage Survey (FDS) - part of the European-wide Level I ronitoring network - predicted a $24 \%$ decrease in survival probability for Norway spruce in pure stands at age 120 when unfavorable changes in climate conditions were assumed. Increasing species admixture greatly reduced the negative effects of unfavorable climate conditions, resulting in a decline in survival probabilities of only $7 \%$. We conclude that future studies of forest management under climate change as well as forest policy measures need to take this, as yet unconsidered, strongly advantageous effect of tree species mixture into account. 


\section{Introduction}

In Central European forests, long production periods prevail, and thus, the success of forest management depends to a great extent on tree survival. It has long been assumed that tree survival is also influenced by tree species mixture (Gayer, 1886), and several scientific studies have provided evidence for this assumption (Griess \& Knoke, 2011). However, the increase in stand resistance resulting from the admixture of broadleaves in coniferous stands has only recently been quantified (Griess et al., 2012). While Griess et al. (2012) based their analysis on current climate conditions, our goal was to investigate the resistance of mixed forests under climatic change.

The consequences of climate change for biodiversity, forests and mortality of tree species have been intensively investigated at the global level (Allen et al., 2010; Araújo \& Williams, 2000; Blennow et al., 2010; Hanewinkel et al., 2010; Hanewinkel et al., 2012; Hansen et al., 2001; Iverson \& Prasad, 2001; Rigling et al., 2013; Seidl et al., 2007; Seidl et al., 2011; Yang et al., 2003). Difficulties in modeling these consequences are caused by the fact that forests are complex ecosystems that are affected not only by gradually changing climatic conditions, but also by a change of the regime of extreme weather and also biotic f vents.

In southern-Germany, potential effects of climate change on the dominant tree species have mainly been assessed using species distribution models (Falk \& Mellert, 2011; Hanewinkel et al., 2010; Mellert et al., 2011), models describing disturbances such as storms (e.g. Albrecht et al., 2012; Schindler et al., 2009), or models offering climate-dependent hazard-functions (Nothdurft, 2013). These models, however, have not distinguished between mixed-species and pure forest stands. 
A dataset that is particularly appropriate for modeling tree survival in pure and mixed forest stands are mortality data of single trees from the Forest Damage Survey (FDS) that are part of the European-wide Level I monitoring network (Fischer et al. 2010), due to the very high temporal resolution of data collection; surveys are done every 1 to 2 years (Augustin, et al. 2009). However, up to now, studies using FDS data for survival analysis have been based on small datasets and have not included climate variables (Griess et al., 2012; Staupendahl \& Zucchini, 2011). Here, for the first time, survival analysis was done using FDS data from three different federal states in southern Germany - Baden-Württemberg (BW), Bavaria (BV) and Rhineland-Palatinate (RP) - representing 4.6 M ha of forest land and covering a broad spectrum of climate conditions. We have augmented the previously published method of assessing age-dependent survival probabilities of Norway spruce (Picea abies Karst.) and European beech (Fagus sylvatica L.) using FDS data (Griess et al., 2012; Staupendahl \& Zucchini, 2011) by including the consideration of climate variables in order to answer two questions:

- Do climate variables such as precipitation and temperature have an effect on the agedependent survival probability of Norway spruce and European beech?

- Is Norway spruce in mixed forests more or less affected by changing climate conditions than in pure stands? 


\section{Materials and methods}

Data

Established in 1983/84, FDS is a program that monitors forest damages in Germany in order to provide annual assessments of the condition of Germany's forests, especially in light of previous observations of increasing damages (Augustin et al., 2009). The monitoring program is part of the 'Data on Crown Condition of the systematic grid' (Level I) from the 'International Co-operative Programme on Assessment and Monitoring of Air Pollution Effects on Forests' (ICPF) in Europe (Fischer et al 2010). Based on the data collected in these surveys, national-level reports are released which contain mainly assessments of defoliation and discoloration of tree crowns. In addition to observations of damage to individual trees, information about the characteristics of the surrounding stand is recorded at every sample plot.

While data collection methods do vary slightly across the different German federal states, all FDS plots are located based on a systematic grid $(4 \times 4 \mathrm{~km}, 8 \times 8 \mathrm{~km}$ or $16 \times 16$, depending on year and state); a sample plot is established at each grid point that falls within land designated as forest. In BW and RP, data from 24 sample trees are gathered at each r oint. The trees are located in four clustered subplots, each of which is centered on a point at a specific distance from the original grid point in each of the four cardinal directions, i.e. the 6 trees nearest to this point are recorded (Augustin et al., 2009; Griess et al., 2012). In Bavaria, an average of 45 sample trees, each with a minimum age of 60 years, are chosen at every sample point. In general, only dominant trees are selected as sample trees. By this Staupendahl \& Zucchini (2011) showed that the percentage of dominant trees (computed from stem numbers) represented the percentage of area occupied by the regarding trees species quite appropriately. Furthermore, dominant trees are more important for the future 
development of more or less even-aged stands and thus form the economically important stand layer (Staupendahl \& Zucchini, 2011). The analysis of mortality rates for lower social tree classes being mainly affected by light-induced competition was not goal of our study.

In each subsequent survey, the trees from the previous survey are located and their new measurements recorded. In the event of the death of a sample tree, the next nearest tree to the subplot center is chosen as a replacement. Since 1994, a "survival status" code which includes information as to the cause of death of each individual tree has been documented as well. These data are available from 1995 on for each of the three states studied here. The development of the sample trees since that time was analyzed in our study in accordance with the study by Griess et al. (2012). In BV, beginning in 2005, the grid was changed in order to directly correspond to the plots of the soil condition survey, unfortunately leading to a discontinuation of the individual tree tracing. Table 1 contains a summary listing of the survival status codes for each tree (spruce and beech) recorded from 1995-2005 in the three federal states.

The survival analysis described here was based on information from 2334 plots rontaining a total of 64356 trees, of which 27804 are spruce $(43 \%)$ and 11702 are beech (18 $\%)$. We focused our study on these two species as the most important hardwood and softwood species in the studied area. Other tree species showed comparatively low amount of death trees during the analyzed time period. The causes of individual tree failure (death) between 1995 and 2005 were separated into reasons considered 'relevant' for our survival analysis (failures due to abiotic or biotic reasons) and 'non-relevant' reasons (failures due to competition, felling or unknown reasons) (Table 1). During this time period, an average of 6 $\%$ of spruce trees across all sites died due to relevant reasons $-5 \%$ in BW, $7 \%$ in BV and 9 
$\%$ in RP. Beech showed lower failure rates, with a $2 \%$ average over the entire data set, as well as in both BW and BV, and an average of $3 \%$ in RP.

In addition to the development of the tree status, variables describing stand characteristics were gathered at each plot: This information was used here to assess the influence of tree species mixture and soil conditions on survival (Table 2). In order to consider mixture, a ratio was calculated depending on how many trees of other species were found among the sample trees of each plot (spruce-other species (mainly beech) and beechother species). Three classes were defined for spruce in accordance to Griess et al. (2012) and also for beech balancing the occupancy of classes with the analyzed trees (Table 2). Soil conditions were integrated into the analysis in two ways. First, water supply was considered by grouping each of the plots into one of 5 classes (wet $\&$ moist, fresh, mesic fresh, (mesic) dry, periodically wet), whereby the class size regarding the number of plots could be balanced Then, nutrient supply was considered, as defined by 3 groups: rich, medium, and poor.

To assess the influence of climate variables on survival, monthly data on precipitation and temperature at each inventory point were collected from the climate normal period (19502000) of the WorldClim-database (Hijmans et al., 2005). The climate variables considered were accumulated precipitation $(\mathrm{P})$ and mean temperature $(\mathrm{T})$ during the vegetation period (from the beginning of May through the end of September - shortened to '5to9'). In subsequent models, we tested whether the variable, 'mean temperature in winter' (from January to March - abbreviated to 'T_1to3') or the variable 'mean temperature in January' (T_1) were better predictors of failure. For each of the climate variables, three sub-groups were defined by locating breakpoints in the data, which resulted in an equal distribution of the total of 2334 plots across three groups (Table 2). 
The spatial distribution of precipitation and temperature was different across the three states (Fig. 1). High precipitation levels were found mainly in the south - for example, in the Black Forest (BW), in the area of Bavaria just north of the Alps where clouds are retained, and in the Bavarian Forest (BV). RP received only low to medium amounts of precipitation. High temperatures occurred mostly in BW and RP, whereas plots in BV were primarily in the 'cold' and 'medium' groups.

\section{Kaplan-Meier survival analysis}

The focus of the survival analysis was on time $T$ - the age of a tree at the time of its death or failure. The distribution of $T$ is described by the density function $f(t)$, the distribution function $F(t)$, the hazard function $h(t)$ or the survival function $S(t)$, whereby $t$ is a specific value of $T$ (Griess et al., 2012; Staupendahl \& Zucchini, 2011). While $h(t)$ focuses on failure in terms of the current potential to fail or die, $S(t)$ represents the probability that an individual survives the time, $t$ (Kleinbaum \& Klein, 2012). In the Kaplan-Meier survival analysis, as an example of a non-parametric approach, $S(t)$ was defined as follows (Kleinbaum \& Klein, 2012; Staupendahl \& Zucchini, 2011):

$$
S(t)=\prod_{t_{i} \leq t}\left(1-\frac{d_{i}}{n_{i}}\right)
$$

Wherein $d_{i}$ stands for the individuals that die during period $t_{i}$, and $n_{i}$ represents the total of analyzed subjects at the beginning of each period $i$. The Kaplan-Meier estimator, which maximizes the likelihood of $S(t)$, offers a first overview of the development of the survival probability based on age. 


\section{Accelerated Failure Time Analysis}

In parametric survival models, survival time follows a specific distribution. We chose the Weibull distribution (Weibull, 1951) and the corresponding survival function $S(t)$ defined as (Staupendahl \& Zucchini, 2011):

$$
S(t)=\exp \left[-\left(\frac{t}{\beta}\right)^{\alpha}\right], \quad t \geq 0
$$

The Weibull distribution is, therefore, only described by two parameters - the scaleparameter $\beta$ and the shape-parameter $\alpha$. The latter parameter is often accentuated showing age-related risk denoting increasing $(\alpha>1)$, decreasing $(\alpha<1)$ or constant $(\alpha=1)$ hazard rates (Griess et al., 2012; Staupendahl \& Zucchini, 2011).

The influence of covariates was analyzed using AFT models. The calculation was done, using the 'survreg' function in R (R Core Team, 2013) which parameterizes the Weibull distribution via a location-scale model and uses a log transformation that leads to the AFT model (Therneau, 2013). In the AFT model, the effects of covariates that cause either a contraction or an extension of survival time are represented by a baseline survival function (Kleinbaum \& Klein, 2012; Staupendahl \& Zucchini, 2011).

Whether or not a covariate had a significant effect on survival was tested beforehand using R-code, according to Glomb (2007). This analysis (Collett, 2003) contained three steps where the likelihood-ratio test was used to compare the fit of the models tested. In our study, this comparison was done between a complex and a simple model with a critical value of 0.01. Initially, the covariates were tested solely. Then, the significant variables from step 1 were analyzed as to whether or not they still had a significant effect on survival time in combination with the other covariates. Finally, the variables which were not found to be significant in step 1 were tested together with those remaining from step 2 (for an example of 
this progress see Griess et al., 2012). Only the covariates which showed a significant effect in combination with other significant covariates were later used in the AFT model.

\section{Results}

\section{Kaplan-Meier survival analysis}

Kaplan-Meier survival analysis was used to get a first overview of the development of survival probability in each of the three groupings within each climatic variable (Fig. 2a-dFig. 2). Higher survival probabilities were found for spruce trees in plots with high precipitation levels and low temperatures. Furthermore, trees reached more advanced ages under these conditions. One exception to this finding was in the temperature range, T_5to9, where spruce trees in the 'warm' plots had a higher survival probability, even though they did not live as long as those in the other classes (Fig. 2b). The survival probability for spruce trees was between 0.8 and 0.9 at the age of 100. This was higher than the value of around 0.7 found by Griess et al. (2012) who analyzed only data from RP where a higher percentage of trees failed (Table 1).

The situation was different and more complex for beech. Differences in precipitation and temperature in the vegetation period (Figs. 3a and b) showed similar survival curves across the three classes, and differences among them were only found at an age of about 150 , when low precipitation levels and medium temperatures led to a higher survival probability. Temperature $T_{-}$1to3 and $T_{-} 1$ showed a low survival probability at younger ages in the warm group but at an age of approximately 150 , beech seemed to be more negatively affected by cold temperatures. 


\section{AFT Models}

As mentioned above, the parametric AFT models used to assess the influence of different covariates on survival time were formed and all covariates (see Table 2) - water, nutrient supply, spruce ratio, precipitation and temperature - were analyzed with regard to their effect on the survival of spruce. The same multi-step analysis proposed by Collett (2003) was used here (Griess et al., 2012). Three AFT models were run - one for each of the three different temperature variables; T_5to9, T_1to3 and T_1. In all cases, nutrient supply was the only covariate that showed no significant effect on survival time ( $p$-value $>0.01$ ) and, therefore, it was not included in the AFT models. The log-likelihood was used to compare the model fit among the three AFT models - the higher this value, the better the model fit. The AFT model containing covariate, T_5to9, showed a log-likelihood of -12972.9 , the model with T_1to3, -12937.5, and the model with T_1, -12939.7. Following the results of a loglikelihood analysis, we decided to present the results of the AFT model for T_1 here, because this model most clearly shows the main results which were consistent across all of the model variants we tested. The covariates that in the end were integrated in the model are listed in Table 3.

Table 3 shows the coefficient values of the covariates which were integrated into the AFT model. Positive values denote an extension of survival time (i.e. an increase in survival probability) and negative values indicate the contrary. The reference value is always the 'Intercept', which contains medium characteristics of the tree species ratio, water supply, P_5to9 and T_1; for spruce, namely, a spruce ratio of 81-99 \%, fresh soil conditions, medium precipitation during the vegetation period, and medium temperature in January (see also Table 2). When a similar situation was considered, but with a spruce ratio $<=80 \%$, the value of the intercept was raised by 0.1771 (Table 3). Also, the acceleration factor (calculated by 
$\exp (0.1771)=1.1936)$ shows that the survival time would increase by this factor (Kleinbaum \& Klein, 2012).

The AFT model for beech with $T_{-} 1$ contained only water supply and temperature as significant covariates. The analysis showed only small differences in survival probabilities for the different temperature classes, as evidenced by the low number of failed trees. Furthermore, the soil condition had a stronger effect on the survival probability of beech than the amount of accumulated precipitation in the vegetation period, which, as previously mentioned, was found to be statistically insignificant. Wet and dry soil conditions were especially disadvantageous for the survival of beech trees (Table 4). Under the current climatic situation in the study area, the well-known sensitivity of beech to low temperatures, and especially to drought (Pretzsch et al., 2012; Rötzer et al., 2013), is not ('yet' in terms of drought) clear enough to have a noticeable effect on survival probability of beech.

\section{The importance of tree species mixture}

Using the calculated coefficients from the AFT model of spruce, the survival probability at age 120 (S120) was computed for different combinations of climate and soil conditions (Table 5). High precipitation levels and low temperatures (T_1) were merged to form a class referred to as 'favorable' climate while 'unfavorable' climate was used to indicate low precipitation levels and high temperatures. In addition, the different classes of water supply were combined to create 'good' ('fresh' and 'mesic fresh') and 'bad' soil condition classes ('wet \& moist', '(mesic) dry' and 'periodically wet').

Using the scale and shape parameters of the Weibull function, curves of survival probabilities for both the worst-case (unfavorable climate, bad soil) scenario and the best situation (favorable climate, good soil) displayed separately for mixed and pure spruce stands 
are shown in Fig. 4. The effect of tree species mixture was as indicated by the lower survival probabilities of spruce in pure stands. Furthermore, we were able to show that rotation periods in pure stands would have to be shortened to 85 years (under unfavorable climate and bad soil conditions) or 90 years (under favorable climate and good soil conditions) to achieve survival probabilities similar to those of mixed stands of spruce at age 120 .

The total results depicted in Table 5 show primarily an increase in survival probability (by a minimum of $5 \%$ and a maximum of $27 \%$ ) with an increase in the proportion of admixed broadleaved tree species which is consistent with the results of previous research (Griess et al., 2012). A change in climate to conditions with low precipitation levels and warm temperatures, however, caused significant reductions from $6 \%$ to $24 \%$ in the survival probabilities for spruce at age 120. The well-documented vulnerability of spruce to high temperatures and especially, to low levels of precipitation (Lindner et al., 2010) was, therefore, supported by our model.

Ultimately, spruce in mixed stands was much less affected than that in pure stands, thus illustrating the possibility for mitigation of the adverse effects of climatic change through forest management. Compared to the decrease in S120 of $24 \%$ found in pure spruce stands on bad soil conditions under possible future changes in climate the survival of spruce in mixed forests was only moderately reduced under climatic change (-7\%) (Table 5).

This article is protected by copyright. All rights reserved. 


\section{Discussion}

We wanted to answer two questions with our analysis of the FDS data: With regard to the first question, namely

- Do climate variables such as precipitation and temperature have an effect on the agedependent survival probability of Norway spruce and European beech?,

we were able to show that climate variables (here precipitation and temperature) clearly have a larger impact on survival probability of spruce than soil conditions. These results contradict those of Griess et al. (2012) who showed that bad soil conditions have a clear positive effect on survival time, which can be explained by the resulting decrease in tree heights and therefore lower level of risk due to potential damage from storms.

In Central Europe Norway spruce is expected to be negatively affected by changing climate conditions such as a shift of precipitation to winter and, as a result, occurrences of drought during the vegetation period and an increase in annual mean temperature (Lindner et $a l ., 2010)$. Due to that a conversion of the forests in southern Germany to a lower proportion of spruce mainly in favor of beech has taken place in the recent years (Hanewinkel et al., 010). The sensitivity of spruce to higher temperatures and particularly to low levels of precipitation was illustrated in the results of the current study, as indicated by a decrease in survival probabilities of up to $24 \%$ at age 120. Pure stands and bad soil conditions strengthened the vulnerability to unfavorable climatic conditions.

As mentioned above, in terms of adaptation to climate change, beech is often thought to be more suitable than spruce in southern Germany. In actuality, the range of beech is mainly limited by low temperatures, for example, in the Alps, and the correspondingly shorter vegetation period (Bolte et al., 2007). This sensitivity to low temperatures in January (T_1) or 
January to March (T_1to3) was only shown in the results of the Kaplan-Meier analysis, where older trees seemed to be more affected by cold temperature than younger trees. The parametric AFT model though, did not display this effect. This could be due to the low total number of failed beech trees in the dataset.

In contrast to temperature, precipitation was not significant for the survival of the beech trees in the dataset used for this analysis. However, drought is also a condition which has been shown to limit the growth of beech (Bolte et al., 2007; Pretzsch et al., 2012; Rötzer et al., 2013). Under the current climatic situation in the study area, this factor has not yet been critical enough to have a noticeable effect on the survival probability of beech.

The AFT models for the temperature variables $T_{-} 1$ to 3 and $T_{-} 1$ provided a better explanation of survival time for spruce and beech than the model with T_5to9. This can be explained by several factors. With reference to spruce and young beech trees, warmer temperatures in winter most likely support the development of pathogens and an increase in the level of browsing by herbivores (Ayres \& Lombardero, 2000; Lindner et al., 2010). The temperature in the vegetation period, in contrast, is not as important for survival as, for example, the level of precipitation during this time period, which directly affects the health of individual trees, especially spruce trees.

With regard to the second question we addressed with our analysis:

- Is Norway spruce in mixed forests more or less affected by changing climate conditions than in pure stands?

our results clearly show that spruce in mixed stands was much less affected by changing climate conditions than spruce in pure stands. Compared to the dramatic decrease in S120 of 
$24 \%$ found in pure spruce stands on bad soils under predicted future changes in climate, the survival of spruce in mixed forests was reduced only moderately under climatic change $(-7 \%)$.

Further, Weibull-distributed curves of survival probability for both the worst-case (unfavorable climate, bad soil) scenario and the best situation (favorable climate, good soil) when differentiating between mixed and pure spruce stands clearly showed the advantageous effect of tree species mixture through the resulting higher survival probabilities. Therefore, rotation periods in pure stands would have to be shortened to 85 years (under unfavorable climate and bad soil conditions) or 90 years (under favorable climate and good soil conditions) in order to achieve survival probabilities similar to those found in mixed stands at age 120 .

A naturally higher variation in tree ages may also be a structural property, which may have contributed to a higher stand resistance (e.g. Hanewinkel et al. 2014) of spruce in mixed stands. However, the majority of stand situations analyzed have been largely even-aged showing a difference between maximum and minimum tree age of 20 to 30 years. This age difference does not form a significant structural diversity. Beech trees are usually regenerated earlier than spruce to create mixed stands because beech grows slower than spruce. This type $r \mathrm{f}$ timing is designed to form mixed stands where tree species achieve similar heights in the older stands so that neither species is outcompeted. It is thus unlikely that age structure is a dominating factor to explain higher resistance of spruce in mixed stands against natural hazard. Even if a greater age difference was in part responsible for higher resistance of spruce, we argue that this is inherent in mixed forests and very hard to be achieved in pure forests. 


\section{Using Level-I-Data for mortality analysis}

The appropriateness of the FDS data for survival time analysis has already been shown in several studies (Griess et al., 2012; Staupendahl, 2011; Staupendahl \& Zucchini, 2011). Especially the indication of reasons for the death of a tree is an important advantage of FDS compared to other forest inventory data. Here we extended the approaches of these studies to include the effects of climate covariates and to cover a larger spatial range. The use of data at the level of German federal states facilitated this high spatial resolution and allowed us the opportunity to integrate varying conditions in forests to a satisfactory extent. A further expansion of the study area would be desirable but is aligned with a high time effort of data preparation and intensive contact to data collectors. Furthermore it is yet still uncertain whether or not the information contained in the expanded data set on the reasons why a tree has disappeared is actually complete enough and sufficient to carry out survival time analysis. However, the promising results of the actual study will certainly stimulate new research in this direction.

It should be further mentioned here that survival-relevant data are only collected for trees of at least 60 years of age in Bavaria. The survival probabilities for the tree species =nalyzed here are, therefore, slightly overestimated. Also, the relatively short observation period of 11 years is a constraint of our study which was a direct result of using the FDS dataset, as the grid points of the FDS in Bavaria were slightly changed in 2005 in order to match the National Soil Survey, as previously mentioned. Although the FDS is still in operation, the individual trees identified in 1995 could not be tracked after 2005. However, several significant events such as the storm event known as Lothar (1999) and the extremely dry conditions which occurred in 2003 were included in this time series. 


\section{Consideration of climate change in forest management}

The coefficients calculated using the AFT model can be used to get age-dependent curves of survival probabilities under different climate and soil conditions and for various species mixtures. It would, therefore, be possible to draw conclusions by analogy and, by using climate change scenarios, to help project changes in the future development of managed forests in order to provide support for the decision making of forest owners. Taking our results into account in forestry research about climate change is essential - especially the consideration of adaption options such as mixing tree species to mitigate risks.

In comparison to the option of shortened rotation periods (Köhl et al., 2010), increasing stand resistance by mixing species allows for more moderate or even longer production periods while still limiting production risks to an acceptable level. This offers various additional advantages such as the opportunity to utilize low-cost natural regeneration, a greater amount of flexibility in terms of timing of timber harvests (Jacobsen \& Thorsen, 2003; Knoke \& Wurm, 2006), and ultimately, a higher level of C storage in forest enterprises (Knoke \& Weber, 2006), which means a net mitigation effect on climatic change. Also, the level of provision of other ecosystem services such as recreation and protection will increase f rough the use of near-natural, mixed and longer-living forests (Edwards et al., 2012). Thus, forest policies should further support conversion of European forests from those dominated by spruce monocultures into mixed forests, and future studies of the economic effects of climatic change on forestry should include mixed forests as an effective adaptation option.

This article is protected by copyright. All rights reserved. 


\section{Acknowledgements}

We thank three anonymous reviewers for their comments on the manuscript. The presented study is part of the project "Uncertainty and the bioeconomics of near-natural silviculture", KN 586/7-2, funded by the German Research Foundation (DFG).

\section{References}

Albrecht A, Hanewinkel M, Bauhus J, Kohnle U (2012) How does silviculture affect storm damage in forests of south-western Germany? Results from empirical modeling based on long-term observations. European Journal of Forest Research, 131, 229-247.

Allen CD, Macalady AK, Chenchouni H et al. (2010) A global overview of drought and heatinduced tree mortality reveals emerging climate change risks for forests. Forest Ecology and Management, 259, 660-684.

Araújo MB, Williams PH (2000) Selecting areas for species persistence using occurrence data. Biological Conservation, 96, 331-345.

Augustin NH, Musio M, Wilpert K von, Kublin E, Wood SN, Schumacher M (2009) Modelling spatio-temporal forest health data. Journal of the American Statistical Association, 104, 899-911.

Ayres MP, Lombardero MJ (2000) Assessing the consequences of global change for forest disturbance from herbivores and pathogens. Science of The Total Environment, 262, 263286.

Blennow K, Andersson M, Sallnäs O, Olofsson E (2010) Climate change and the probability of wind damage in two Swedish forests. Forest Ecology and Management, 259, 818-830.

Bolte A, Czajkowski T, Kompa T (2007) The north-eastern distribution range of European beech a review. Forestry, 80, 413-429.

Collett D (2003) Modelling survival data in medical research. Chapman \& Hall/CRC, Boca Raton, Fla, 391 pp.

Lidwards DM, Jay M, Jensen FS, Lucas B, Marzano M, Montagné C, Peace A, Weiss G (2012) Public Preferences Across Europe for Different Forest Stand Types as Sites for Recreation. Ecology and Society, 17.

Falk W, Mellert KH (2011) Species distribution models as a tool for forest management planning under climate change: risk evaluation of Abies alba in Bavaria. Journal of Vegetation Science, 22, 621-634.

Fischer R, Lorenz M, Köhl M et al. (2010) The Condition of Forests in Europe. 2010 Executive Report. ICP Forests and European Commission, Hamburg and Brussels, 21 pp.

Gayer K (1886) Der gemischte Wald: seine Begründung und Pflege, insbesondere durch Horst- und Gruppenwirtschaft. Paul Parey, Berlin.

Glomb P (2007) Statistische Modelle und Methoden in der Analyse von Lebenszeitdaten.

Diplomarbeit, Carl-von-Ossietzky Universität, Oldenburg. 
Griess VC, Acevedo R, Härtl F, Staupendahl K, Knoke T (2012) Does mixing tree species enhance stand resistance against natural hazards? A case study for spruce. Forest Ecology and Management, 267, 284-296.

Griess VC, Knoke T (2011) Growth performance, wind-throw, and insects: meta-analyses of parameters influencing performance of mixed-species stands in boreal and northern temperate biomes. Candinadian Journal of Forest Research, 41, 1141-1158.

Hanewinkel M, Cullmann DA, Schelhaas M, Nabuurs G, Zimmermann NE (2012) Climate change may cause severe loss in the economic value of European forest land. Nature Climate Change, 3, 203-207.

Hanewinkel M, Hummel S, Cullmann DA (2010) Modelling and economic evaluation of forest biome shifts under climate change in Southwest Germany. Forest Ecology and Management, 259, 710-719.

Hanewinkel M, Kuhn T, Bugmann H, Brang P. (2014) Vulnerability of uneven-aged forests to storm damage. Forestry, 10.1093/forestry/cpu008 (in press.)

Hansen AJ, Neilson RP, Dale VH et al. (2001) Global Change in Forests: Responses of Species, Communities, and Biomes. BioScience, 51, 765-779.

Hijmans RJ, Cameron SE, Parra JL, Jones PG, Jarvis A (2005) Very high resolution interpolated climate surfaces for global land areas. International Journal of Climatology, 25, 1965-1978.

Iverson LR, Prasad AM (2001) Potential Changes in Tree Species Richness and Forest Community Types following Climate Change. Ecosystems, 4, 186-199.

Jacobsen JB, Thorsen BJ (2003) A Danish example of optimal thinning strategies in mixedspecies forest under changing growth conditions caused by climate change. Forest Ecology and Management, 180, 375-388.

Kleinbaum DG, Klein M (2012) Survival Analysis. A Self-Learning Text. Springer, New York.

Knoke T, Ammer C, Stimm B, Mosandl R (2008) Admixing broadleaved to coniferous tree species: a review on yield, ecological stability and economics. European Journal of Forest Research, 127, 89-101.

Knoke T, Weber M (2006) Expanding Carbon Stocks in Existing Forests - A Methodological Approach for Cost Appraisal at the Enterprise Level. Mitigation and Adaptation Strategies for Global Change, 11, 579-605.

Knoke T, Wurm J (2006) Mixed forests and a flexible harvest policy: a problem for conventional risk analysis? European Journal of Forest Research, 125, 303-315.

Köhl M, Hildebrandt R, Olschofksy K et al. (2010) Combating the effects of climatic change on forests by mitigation strategies. Carbon Balance and Management, 5, 8 .

Lindner M, Maroschek M, Netherer S et al. (2010) Climate change impacts, adaptive capacity, and vulnerability of European forest ecosystems. Forest Ecology and Management, 259, 698-709.

Mellert KH, Fensterer V, Küchenhoff H, Reger B, Kölling C, Klemmt HJ, Ewald J (2011) Hypothesis-driven species distribution models for tree species in the Bavarian Alps. Journal of Vegetation Science, 22, 635-646. 
Nothdurft A (2013) Spatio-temporal prediction of tree mortality based on long-term sample plots, climate change scenarios and parametric frailty modeling. Forest Ecology and Management, 291, 43-54.

Pretzsch H, Dieler J, Seifert T, Rötzer T (2012) Climate effects on productivity and resourceuse efficiency of Norway spruce (Picea abies [L.] Karst.) and European beech (Fagus sylvatica [L.]) in stands with different spatial mixing patterns. Trees, 26, 1343-1360.

R Core Team (2013) R. A language and environment for statistical computing. R Foundation for Statistical Computing, Vienna, Austria.

Rigling A, Bigler C, Eilmann B et al. (2013). Driving factors of a vegetation shift from Scots pine to pubescent oak in dry Alpine forests. Global Change Biology 19: 229-240.

Rötzer T, Liao Y, Goergen K, Schüler G, Pretzsch H (2013) Modelling the impact of climate change on the productivity and water-use efficiency of a central European beech forest. Climate Research, 58, 81-95.

Schindler D, Grebhan K, Albrecht A, Schönborn J (2009) Modelling the wind damage probability in forests in Southwestern Germany for the 1999 winter storm 'Lothar'. International Journal of Biometeorology, 53, 543-554.

Seidl R, Baier P, Rammer W, Schopf A, Lexer MJ (2007) Modelling tree mortality by bark beetle infestation in Norway spruce forests. Ecological Modelling, 206, 383-399.

Seidl R, Fernandes PM, Fonseca TF et al. (2011) Modelling natural disturbances in forest ecosystems: a review. Ecological Modelling, 222, 903-924.

Sims A, Kiviste A, Hordo M, Laarmann D, Gadow K von (2009) Estimating tree survival: a study based on the Estonian Forest Research Plots Network. Annales Botanici Fennici, 46, 336-352.

Staupendahl K (2011) Modellierung der Überlebenswahrscheinlichkeit von Waldbeständen mithilfe der neu parametrisierten Weibull-Funktion. Forstarchiv, 82, 10-19.

Staupendahl K, Zucchini W (2011) Schätzung von Überlebensfunktionen der Hauptbaumarten auf der Basis von Zeitreihendaten der Rheinland-Pfälzischen Waldzustandserhebung. Allgemeine Forst- und Jagdzeitung, 182, 129-145.

Therneau T (2013) Survival Analysis. Package 'survival'. Available via http://cran.rproject.org/web/packages/survival/survival.pdf. Accessed 18 Nov 2013.

Veibull W (1951) A Statistical Distribution Function of Wide Applicability. Journal of Applied Mechanics, 18, 293-297.

Yang Y, Titus SJ, Huang S (2003) Modeling individual tree mortality for white spruce in Alberta. Ecological Modelling, 163, 209-222. 


\section{Tables}

Table 1: Survival status/cause of death of the trees recorded from 1990 to 2005 during the European Forest Damage Survey (FDS) in Baden-Württemberg (BW), Bavaria (BV) and Rhineland Palatinate (RP). (N: number; SD: standard deviation)

\begin{tabular}{|c|c|c|c|c|c|c|c|}
\hline \multicolumn{2}{|c|}{ Status } & $\begin{array}{c}\mathrm{N} \\
\mathrm{BW}\end{array}$ & $\begin{array}{c}\mathrm{N} \\
\mathrm{BV}\end{array}$ & $\begin{array}{c}\mathrm{N} \\
\mathrm{RP}\end{array}$ & $\begin{array}{c}\mathrm{N} \\
\text { total }\end{array}$ & $\begin{array}{l}\text { Mean } \\
\text { Age } \\
\text { [years] }\end{array}$ & SD \\
\hline \multicolumn{8}{|c|}{ Spruce } \\
\hline 0 & Existing and living & 8791 & 12176 & 1961 & 22928 & 93,67 & 35,02 \\
\hline 1 & $\begin{array}{l}\text { Existing and living but changed to } \\
\text { suppressed status }\end{array}$ & 141 & 102 & 26 & 269 & 67,75 & 35,72 \\
\hline 2 & $\begin{array}{l}\text { Existing and living but substantially } \\
\text { damaged }\end{array}$ & 63 & 89 & 23 & 175 & 82,21 & 35,52 \\
\hline 3 & Existing but dead or thrown & 170 & 42 & 69 & 281 & 84,43 & 36,23 \\
\hline 4 & Nonexistent due to calamity & 255 & 841 & 169 & 1265 & 96,79 & 30,87 \\
\hline 5 & $\begin{array}{l}\text { Nonexistent due to planned thinning or } \\
\text { harvest }\end{array}$ & 538 & 1068 & 367 & 1973 & 88,24 & 33,41 \\
\hline 6 & $\begin{array}{l}\text { Nonexistent due to unknown reasons } \\
\text { Total }\end{array}$ & $\begin{array}{r}354 \\
10312\end{array}$ & $\begin{array}{r}360 \\
14678\end{array}$ & $\begin{array}{r}199 \\
2814\end{array}$ & $\begin{array}{r}913 \\
27804\end{array}$ & 86,65 & 41,46 \\
\hline \multicolumn{8}{|c|}{ Beech } \\
\hline 0 & Existing and living & 5497 & 3079 & 1695 & 10271 & 98,91 & 43,00 \\
\hline 1 & $\begin{array}{l}\text { Existing and living but changed to } \\
\text { suppressed status }\end{array}$ & 129 & 40 & 47 & 216 & 73,31 & 41,16 \\
\hline 2 & $\begin{array}{l}\text { Existing and living but substantially } \\
\text { damaged }\end{array}$ & 15 & 10 & 11 & 36 & 105,50 & 40,56 \\
\hline 3 & Existing but dead or thrown & 35 & 7 & 17 & 59 & 104,63 & 46,00 \\
\hline 4 & Nonexistent due to calamity & 46 & 42 & 40 & 128 & 98,05 & 49,65 \\
\hline 5 & $\begin{array}{l}\text { Nonexistent due to planned thinning or } \\
\text { harvest }\end{array}$ & 221 & 250 & 192 & 663 & 107,27 & 42,63 \\
\hline 6 & $\begin{array}{l}\text { Nonexistent due to unknown reasons } \\
\text { Total }\end{array}$ & $\begin{array}{r}103 \\
6046 \\
\end{array}$ & $\begin{array}{r}48 \\
3476 \\
\end{array}$ & $\begin{array}{r}178 \\
2180\end{array}$ & $\begin{array}{r}329 \\
11702 \\
\end{array}$ & 87,12 & 55,57 \\
\hline
\end{tabular}

This article is protected by copyright. All rights reserved. 
Table 2: Covariates considered in the survival analysis of spruce and beech under differing climate and soil conditions, and the number of plots falling within each value category

\begin{tabular}{|c|c|c|c|}
\hline Covariate & Group & Data area & Number of plots \\
\hline \multirow{6}{*}{ Tree species ratio } & \multirow{2}{*}{1} & Spruce: $=100 \%$ & 280 \\
\hline & & Beech: $=100 \%$ & 69 \\
\hline & \multirow{2}{*}{2} & Spruce: $81 \%-99 \%$ & 316 \\
\hline & & Beech: $55 \%-99 \%$ & 268 \\
\hline & \multirow{2}{*}{3} & Spruce: $<=80 \%$ & 967 \\
\hline & & Beech: $<55 \%$ & 928 \\
\hline \multirow[t]{5}{*}{ Water supply } & Wet \& moist & 1 & 372 \\
\hline & Fresh & 2 & 627 \\
\hline & Mesic fresh & 3 & 719 \\
\hline & (mesic) dry & 4 & 450 \\
\hline & Periodically wet & 5 & 166 \\
\hline \multirow[t]{3}{*}{ Nutrient supply } & Poor & 1 & 495 \\
\hline & Medium & 2 & 1203 \\
\hline & Rich & 3 & 636 \\
\hline \multirow[t]{3}{*}{ P_5to9 } & Low & $<363 \mathrm{~mm}$ & 783 \\
\hline & Medium & $363-457 \mathrm{~mm}$ & 766 \\
\hline & High & $>457 \mathrm{~mm}$ & 785 \\
\hline \multirow[t]{3}{*}{ T_5to9 } & Cold & $<14.50{ }^{\circ} \mathrm{C}$ & 774 \\
\hline & Medium & $14.50-15.21^{\circ} \mathrm{C}$ & 787 \\
\hline & Warm & $>15.21^{\circ} \mathrm{C}$ & 773 \\
\hline \multirow[t]{3}{*}{$T_{-}$1to3 } & Cold & $<0.33{ }^{\circ} \mathrm{C}$ & 774 \\
\hline & Medium & $0.33-1.26{ }^{\circ} \mathrm{C}$ & 769 \\
\hline & Warm & $>1.26{ }^{\circ} \mathrm{C}$ & 791 \\
\hline \multirow[t]{3}{*}{$\mathrm{T}_{-} 1$} & Cold & $<(-1.60){ }^{\circ} \mathrm{C}$ & 812 \\
\hline & Medium & $(-1.60)-(-0.70){ }^{\circ} \mathrm{C}$ & 743 \\
\hline & Warm & $>(-0.70){ }^{\circ} \mathrm{C}$ & 779 \\
\hline
\end{tabular}

This article is protected by copyright. All rights reserved. 
Table 3: Coefficients obtained for each variable retained in the AFT model used to assess survival probabilities for spruce in pure stands $(\mathrm{SD}=$ standard deviation, $z=$ standard score, $p=p$-value).

\begin{tabular}{|c|c|c|c|c|}
\hline & Coefficients & $\mathrm{SD}$ & $z$ & $p$ \\
\hline (Intercept) & 5.3318 & 0.0282 & 189.3846 & 0.0000 \\
\hline Spruce ratio 1 & -0.1689 & 0.0179 & -9.4086 & $5.03 \mathrm{E}-21$ \\
\hline Spruce ratio 3 & 0.1771 & 0.0188 & 9.4161 & $4.68 \mathrm{E}-21$ \\
\hline Water supply 1 & -0.0610 & 0.0194 & -3.1469 & 0.0017 \\
\hline Water supply 3 & -0.1145 & 0.0223 & -5.1311 & $2.88 \mathrm{E}-07$ \\
\hline Water supply 4 & -0.0258 & 0.0308 & -0.8362 & 0.4031 \\
\hline Water supply 5 & -0.0872 & 0.0300 & -2.9061 & 0.0037 \\
\hline P_5to9 1 & -0.0303 & 0.0235 & -1.2897 & 0.1971 \\
\hline P_5to9 3 & 0.1277 & 0.0179 & 7.1458 & $8.95 \mathrm{E}-13$ \\
\hline $\mathrm{T}_{-} 11$ & 0.1932 & 0.0179 & 10.7696 & $4.79 \mathrm{E}-27$ \\
\hline $\mathrm{T}_{-} 13$ & 0.0665 & 0.0265 & 2.5121 & 0.0120 \\
\hline $\log ($ scale $)$ & -1.1984 & 0.0181 & -66.1072 & 0.0000 \\
\hline
\end{tabular}

Table 4: Coefficients obtained from the AFT model including T_1 for beech $(\mathrm{SD}=\operatorname{standard}$ deviation, $z=$ standard score, $p=$ p-value)

\begin{tabular}{|c|c|c|c|c|}
\hline & Coefficients & $\mathrm{SD}$ & $z$ & $p$ \\
\hline (Intercept) & 6,4782 & 0,1169 & 55,4303 & 0,0000 \\
\hline Water supply 1 & $-0,2248$ & 0,0865 & $-2,5984$ & 0,0094 \\
\hline Water supply 3 & 0,0463 & 0,0708 & 0,6532 & 0,5136 \\
\hline Vater supply 4 & $-0,0490$ & 0,0760 & $-0,6439$ & 0,5196 \\
\hline Water supply 5 & 0,2374 & 0,1657 & 1,4328 & 0,1519 \\
\hline $\mathrm{T}_{-} 11$ & $-0,0509$ & 0,0862 & $-0,5911$ & 0,5545 \\
\hline $\mathrm{T}_{-} 13$ & $-0,4061$ & 0,0758 & $-5,3566$ & $8,48 \mathrm{E}-08$ \\
\hline $\log ($ scale $)$ & $-0,9542$ & 0,0542 & $-17,5976$ & $2,57 \mathrm{E}-69$ \\
\hline
\end{tabular}

This article is protected by copyright. All rights reserved. 
Table 5: Survival probability for spruce at age 120 (S120), calculated using the coefficients of the AFT model. (Percentages in brackets refer to the percentage change in relation to the pure spruce stand. Percentages of differences between climate and soil conditions are shown in relation to the bad specification.)

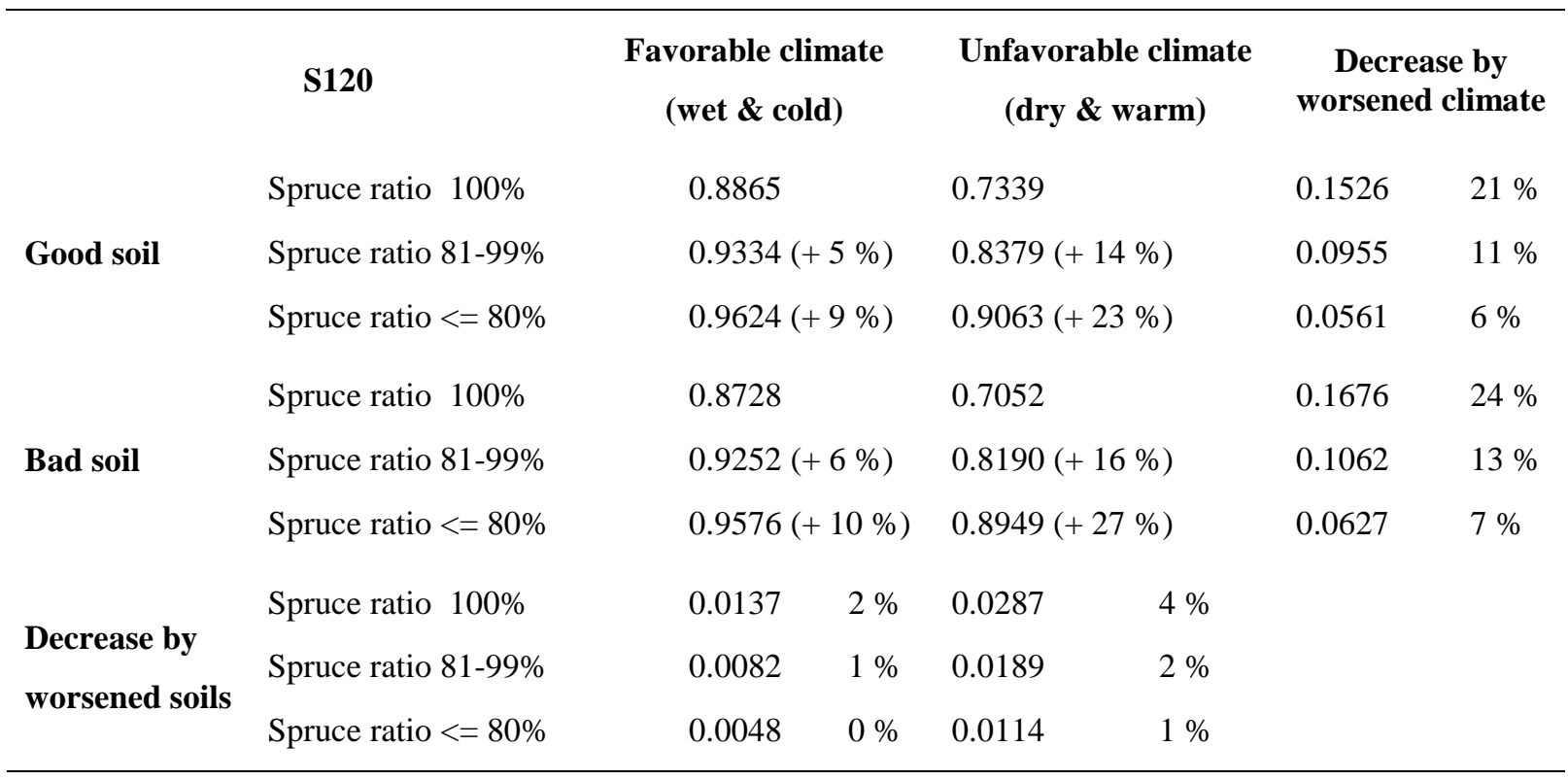

This article is protected by copyright. All rights reserved. 


\section{Figure legends}

Fig. 1: Spatial distribution of the climatic variables (a) P_5to9, (b) T_5to9, (c) T_1to3, (d) T_1 across the three federal states RP (north-west), BW (south-west), BV (south-east)

Fig. 2: Survival probability of spruce based on Kaplan-Meier analysis for covariates (a) $\mathbf{P}$ _5to9, (b) T_5to9, (c) T_1to3 and (d) T_1

Fig. 3: Survival probability of beech based on Kaplan-Meier analysis for covariates (a) P_5to9, (b) T_5to9, (c) $T_{-} 1$ to3 and (d) $T_{-} 1$

Fig. 4: Weibull-distributed survival probabilities for spruce for favorable/unfavorable climate and $\mathrm{good} / \mathrm{bad}$ soil conditions
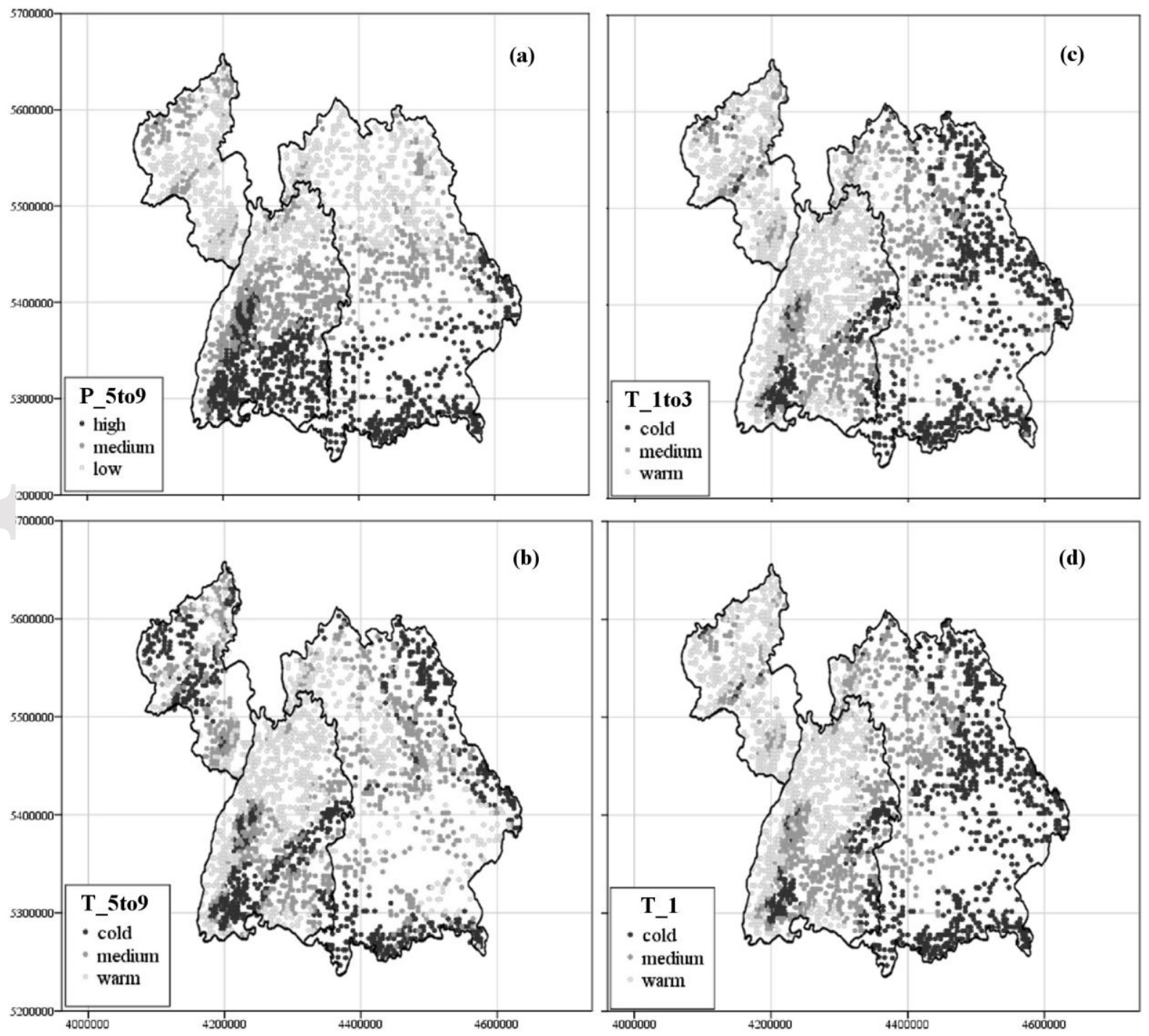

This article is protected by copyright. All rights reserved. 

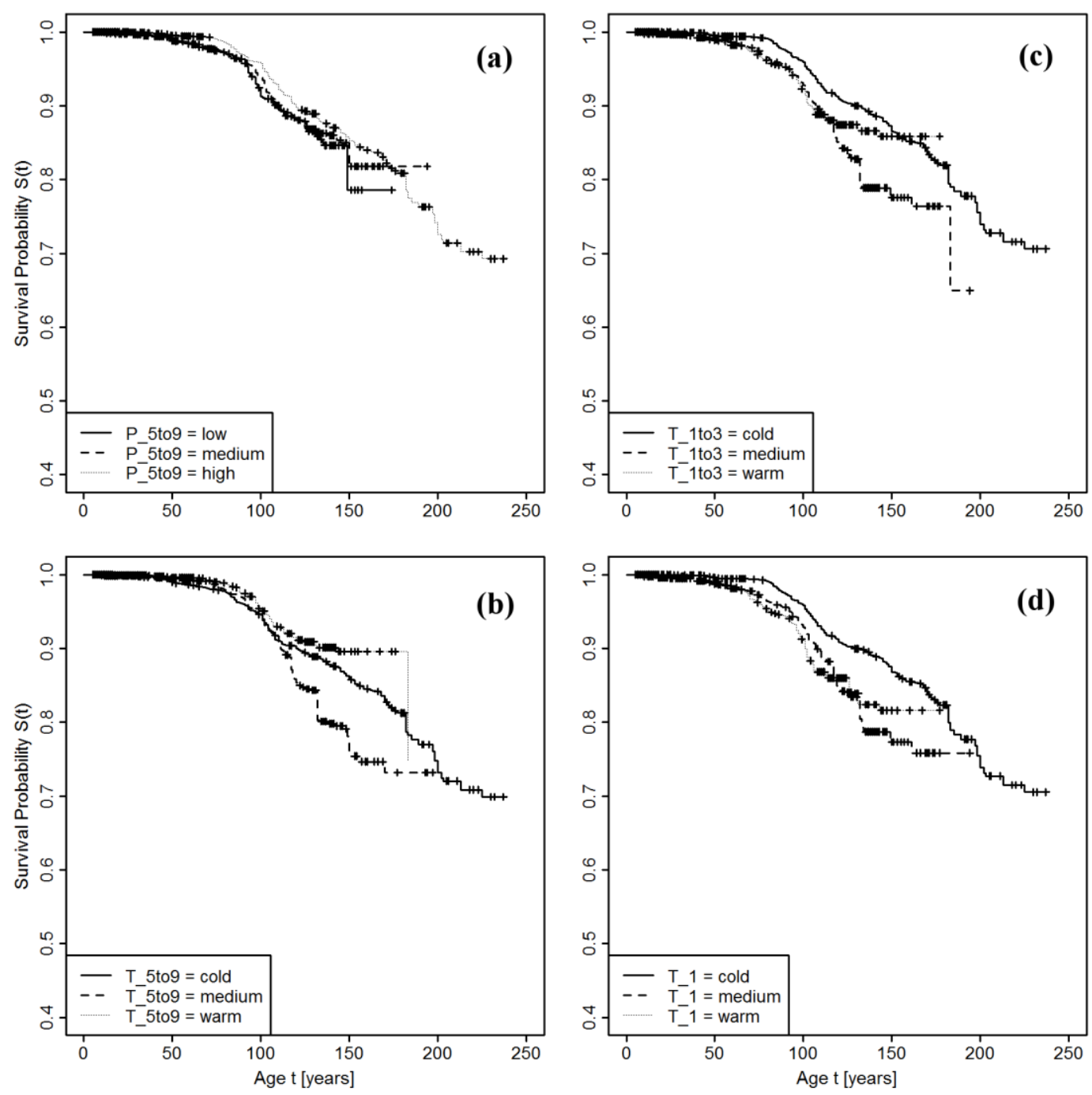

This article is protected by copyright. All rights reserved. 

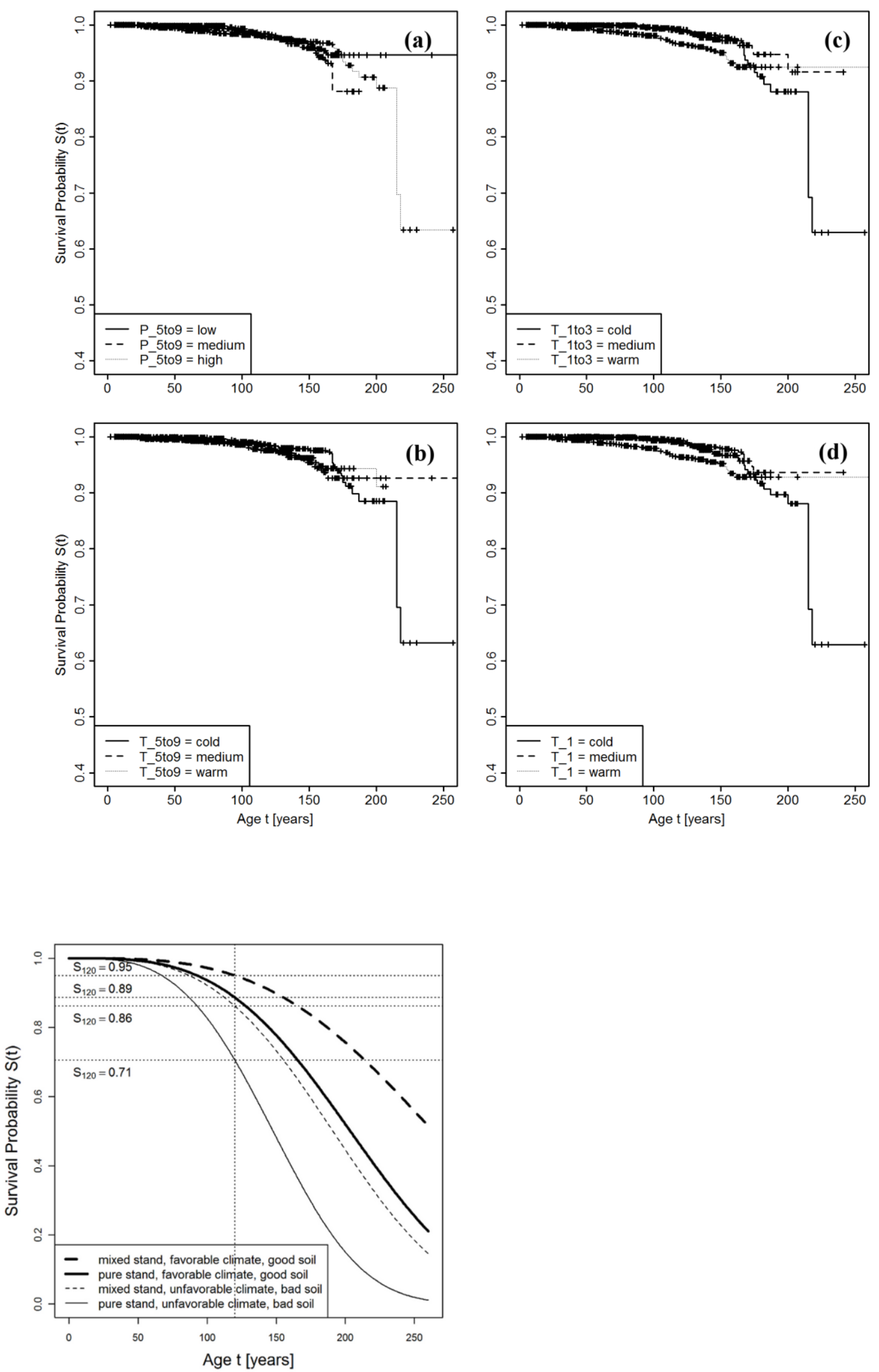

This article is protected by copyright. All rights reserved. 